03

\title{
Переход горения в детонацию в спиралевидных каналах
}

\author{
() С.В. Головастов, А.Ю. Микушкин, В.В. Голуб \\ Объединенный институт высоких температур РАН, \\ 125412 Москва, Россия \\ e-mail: golovastov@yandex.ru
}

(Поступило в Редакцию 24 ноября 2016 г.)

\begin{abstract}
Экспериментально исследован процесс перехода горения в детонацию в водородно-воздушных смесях в спиралевидных каналах. Спиралевидный канал создавался в цилиндрической детонационной трубке с расположенной внутри трубки витой лентой. Воспламенение газовой смеси осуществлялось с помощью искрового разрядника. Определены преддетонационные расстояния в зависимости от конфигурации витой ленты и мольного соотношения компонентов водородно-воздушной смеси. Для четырех конфигураций витой ленты определено тяговое усилие, создаваемое детонационной трубкой вследствие однократного сгорания водородно-воздушной смеси. Определены условия, при которых использование витой спирали может привести к повышению тягового усилия.
\end{abstract}

DOI: $10.21883 /$ JTF.2017.10.44991.2108

\section{Введение}

Использование детонационного режима горения в камерах сгорания обусловлено стремлением к наиболее эффективному преобразованию химической энергии топлива в кинетическую энергию продуктов сгорания. Преимуществом детонационного режима горения над дефлаграционным является более быстрое выделение энергии, что позволяет проектировать устройства с высокой удельной мощностью.

Одним из способов формирования детонации в газах является переход медленного горения в детонацию. В тех случаях, когда горение рассматривается в ограниченных каналах, дополнительное ускорение фронта пламени может быть стимулировано неоднородностями, расположенными внутри канала, например спиралью Щелкина [1]. Расположенные оптимальным образом кольца внутри детонационной трубки также способны турбулизировать фронт пламени, создать области повышенного давления и ускорить формирование детонации [2-4]. Влияние сужения канала, турбулизации потока газа за счет преград и профилированного центрального тела на параметры перехода горения в детонацию и тестовые характеристики детонационной горелки изучены в $[5,6]$. В работе [7] исследовалось влияние турбулизационных камер с расширенным поперечным сечением на переход горения в детонацию (ПГД) в бензо-воздушной смеси. Распространение фронта пламени внутри $U$-образных трубок представлено в работах $[8,9]$.

С другой стороны, расположение кольцевых преград, изгибов и т. п. приводит к потерям суммарного импульса продуктов сгорания, направленного вдоль оси канала. Одним из геометрических объектов, изменяющих форму круглого канала, но снижающим потери импульса продуктов сгорания, может являться спиральная лента, разделяющая канал на две или более частей. При этом уменьшение эффективного диаметра канала в 1.4 раза на некотором конечном участке с помощью спирали может заметно сократить преддетонационное расстояние.

Целью работы было экспериментальное определение динамики перехода горения в детонацию в спиралевидных каналах, определение преддетонационного расстояния и тягового усилия в зависимости от состава водородно-воздушной смеси.

\section{Экспериментальная установка}

Эксперименты по формированию детонации проводились в стальной детонационной трубке длиной $1800 \mathrm{~mm}$ и внутренним диаметром $20 \mathrm{~mm}$ (рис. 1). Один из концов детонационной трубки был открыт. На расстоянии $100 \mathrm{~mm}$ от закрытого конца располагался искровой разрядник. Перед каждым экспериментом новая порция детонационноспособной смеси, подаваемая в трубку у закрытого конца, вытесняла воздух из детонационной трубки через открытый конец. Таким образом, начальное давление в трубке равнялось атмосферному $0.1 \mathrm{MPa}$, а температура равнялась $300 \mathrm{~K}$. Внутри детонационной трубки на расстоянии $1000 \mathrm{~mm}$ от закрытого конца размешалась витая стальная лента. Длина витой ленты равнялась $400 \mathrm{~mm}$, ширина равнялась диаметру канала $20 \mathrm{~mm}$, а толщина составляла $2 \mathrm{~mm}$. Зазоры между лентой и внутренними стенками трубки не превышали $0.2 \mathrm{~mm}$. Использовались три вида лент: плоская пластина, витая лента с шагом винта $200 \mathrm{~mm}$ (два полных оборота), витая лента с шагом $100 \mathrm{~mm}$ (четыре полных оборота).

Водородно-воздушная смесь предварительно составлялась в сосуде объемом 3.31 по парциальным давлениям и выдерживалась в течение $1.0-1.5 \mathrm{~h}$. Использовались три состава смеси с $\mathrm{ER}=0.7,1.0$ и 1.5, где $\mathrm{ER}$ - equivalence ratio, мольный коэффициент избытка водорода. 


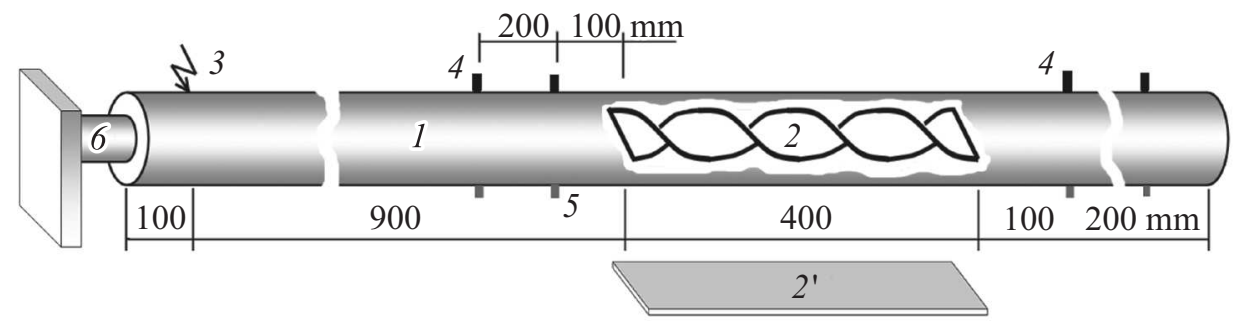

Рис. 1. Схема экспериментальной установки. 1 - детонационная трубка, $2,2^{\prime}-$ витая/плоская лента, 3 - искровой разрядник, 4 - датчики давления, 5 - фотодиоды, 6 - датчик усилия.
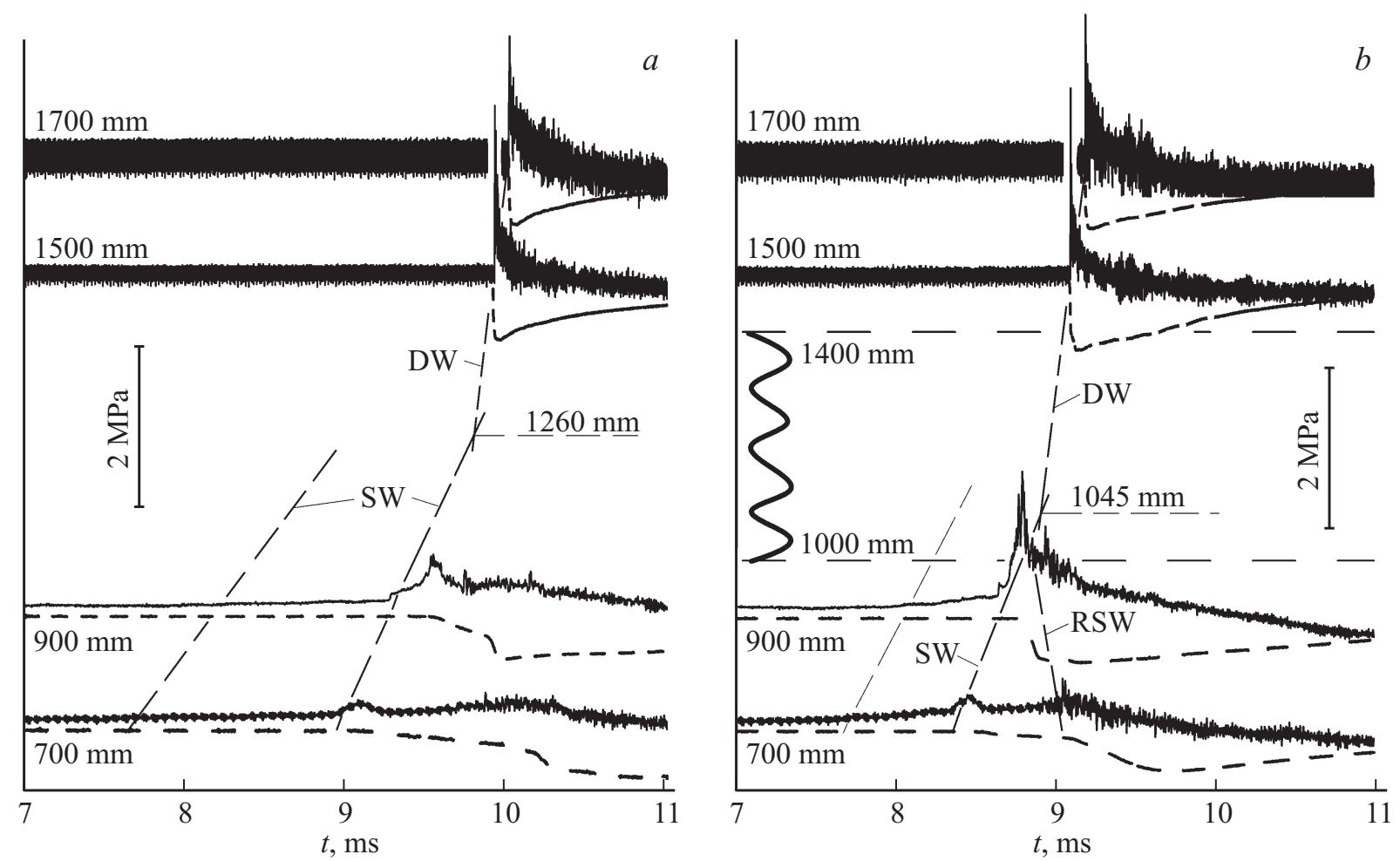

Рис. 2. Осциллограммы давления (сплошные линии) и свечения (штриховые линии) в стехиометрической водородно-воздушной смеси в гладкой трубке $(a)$ и с винтовой лентой с шагом $200 \mathrm{~mm}(b)$. SW - ударная волна, DW - детонационная волна, RSW отраженная ударная волна.

Воспламенение газовой смеси осуществлялось с помощью искрового разрядника, расположенного у закрытого конца трубки. Энергия искрового разряда не превышала $0.1 \mathrm{~J}$, что на два порядка ниже энергии прямого инициирования детонации в канале диаметром $20 \mathrm{~mm}$. Для регистрации волн сжатия и детонации внутри канала использовались пьезоэлектрические датчики давления РСВ113А, расположенные перед витой лентой и после нее. Для регистрации свечения продуктов детонации использовались фотодиоды FD256, установленные в одном сечении с датчиками давления. Тяговое усилие измерялось резистивным датчиком усилия Honeywell FSG15N1A, имеющего временно́е разрешение $200 \mu \mathrm{s}$. Указанного разрешения достаточно для определения тяговых характеристик в течение всего процесса ис- течения продуктов детонации из трубки, длительность которго составляла 10-20 ms.

\section{Результаты экспериментов и обсуждения}

На рис. 2 представлены характерные осциллограммы распространения ударных и детонационных волн для стехиометрической смеси водорода с воздухом в трубке без витой ленты и с витой лентой шагом $200 \mathrm{~mm}$. В том случае, когда в канале отсутствовала витая лента, первая пара датчиков давления регистрировала незначительное повышение давления на $0.2-0.5 \mathrm{MPa}$, вызванное распространением ударной волны впереди фронта горения. 


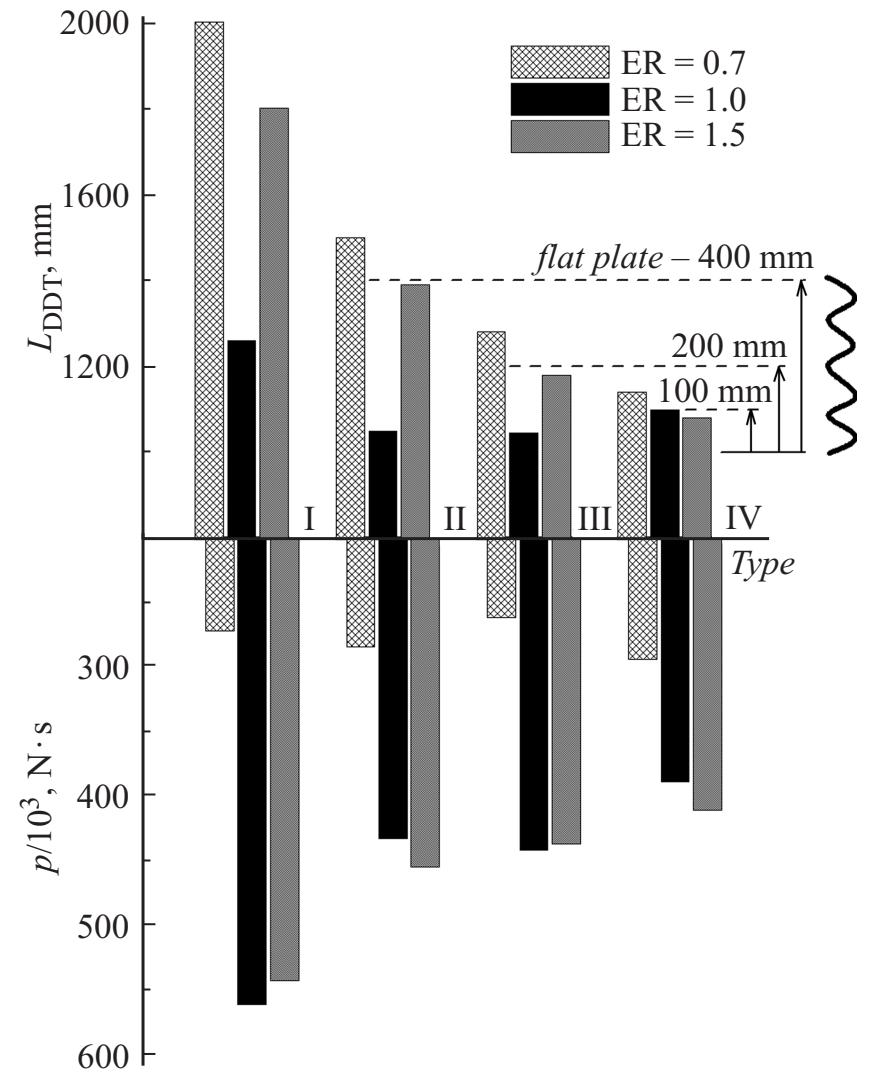

Рис. 3. Преддетонационные расстояния $\left(L_{\mathrm{DDT}}\right)$ и импульсы $(p)$ для четырех типов детонационной трубки: I - гладкая трубка, II - трубка с плоской пластиной, III - витая лента с шагом $200 \mathrm{~mm}$, IV - витая лента с шагом $10 \mathrm{~mm}$. ER - equivalence ratio, мольный коэффициент избытка водорода.

Скорости сформированных таким образом ударных волн (SW) составляли приблизительно $410-590 \mathrm{~m} / \mathrm{s}$. Через $0.2-0.3 \mathrm{~ms}$ после регистрации ударной волны фотодиоды регистрировали свечение фронта пламени. После витой ленты пара датчиков давления регистрировала пересжатую детонационную волну (DW), скорость которой равнялась $2290 \mathrm{~m} / \mathrm{s}$ и превышала скорость стационарной детонации Чепмена-Жуге $\sim 1950 \mathrm{~m} / \mathrm{s}$, а величина давления на фронте составляла 1.9-2.1 МРа. В данном случае значение преддетонационного расстояния $\left(L_{\mathrm{DDT}}\right)$ составляло около $1260 \mathrm{~mm}$.

В том случае, когда в канале размещалась витая лента с шагом $200 \mathrm{~mm}$, первая пара датчиков давления, расположенная перед витой лентой, также регистрировала ударную волну и повышение давления на $0.3-1.4 \mathrm{MPa}$. Данное повышение давления может быть обусловлено отражением скачков уплотнения от передней кромки витой ленты, площадь сечения которой составляет $40 \mathrm{~mm}^{2}$, что равно $13 \%$ от общей площади сечения трубки. Скорость ударной волны составляла около $690 \mathrm{~m} / \mathrm{s}$. Задержка воспламенения также составляла $0.2-0.3 \mathrm{~ms}$. После витой ленты пара датчиков давления также регистрировала сформированную детонационную волну, имеющую скорость $2120 \mathrm{~m} / \mathrm{s}$ и давление $1.9-2.3 \mathrm{MPa}$. Однако преддетонационное расстояние в данном случае снизилось до $1045 \mathrm{~mm}$.

На рис. 3 представлены значения преддетонационных расстояний для трех составов водородно-воздушной смеси и для четырех типов геометрии детонационной трубки. Как и следовало ожидать, использование витых лент в стехиометрической смеси $(\mathrm{ER}=1.0)$ приводит к незначительному сокращению преддетонационного расстояния на $13-17 \%$. Это обусловлено тем, что ширина детонационной ячейки при $\mathrm{ER}=1.0$ составляет около $14-15 \mathrm{~mm}$, т.е. не превышает диаметр детонационной трубки $20 \mathrm{~mm}$ и сравнима с эффективным поперечным размером спиралевидного канала $20 / \sqrt{2} \approx 14.1 \mathrm{~mm}$, так как диаметр гладкой трубки равен $20 \mathrm{~mm}$, а отношение площадей сечения спирального канала и трубки равно 2. Таким образом, динамика перехода горения в детонацию в спиралевидном канале незначительно отличается от динамики перехода в гладком канале. При этом снижение преддетонационного расстояния обусловливается отражением скачков уплотнения от передней кромки витой ленты с последующим взаимодействием с зоной предварительного нагрева реакционной смеси, как это было указано выше.

В том случае, когда использовались богатые $(\mathrm{ER}=$ $=1.5)$ или бедные $(\mathrm{ER}=0.7)$ водородно-воздушные смеси, ширина детонационной ячейки составляла $18-19 \mathrm{~mm}$ и $20-21 \mathrm{~mm}$ соответственно, что сравнимо с диаметром гладкой трубки. Преддетонационное расстояние при этом составляло $1800-2000 \mathrm{~mm}$, что равнялось 90-100 калибрам трубки. Однако, как следует из диаграммы на рис. 3 , использование вставок приводит к сокращению преддетонационного расстояния до $1080-1280 \mathrm{~mm}$. При этом сокращение шага винта до $100 \mathrm{~mm}$ приводило к наибольшему сокращению преддетонационного расстояния, до $40-43 \%$, что сравнимо с преддетонационным расстоянием в стехиометрической смеси $(\mathrm{ER}=1.0)$. Несмотря на то что ширина детонационной ячейки при ER, отличных от единицы, увеличивается и превосходит наименьший поперечный

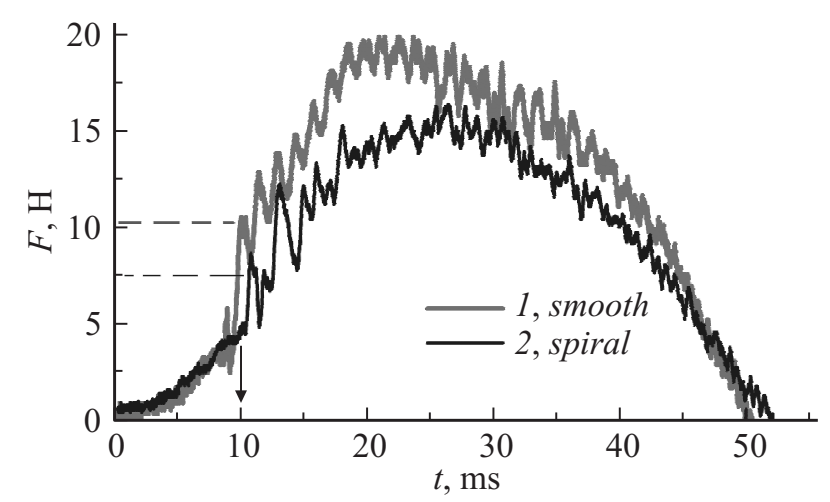

Рис. 4. Осциллограммы усилия в стехиометрической водородно-воздушной смеси в гладкой трубке $(1)$ и с винтовой лентой с шагом $200 \mathrm{~mm}$ (2). 
размер спиралевидного канала, существенное влияние на формирование детонации может оказывать многократное отражение скачков уплотнения на косых стенках витой ленты. Как правило, формирование детонации происходило на длине одного витка для витых лет обоих типов, как это отмечено на диаграмме.

Как показано на рис. 4, тяговое усилие, создаваемое детонационной волной на выходе из детонационной трубки и истекающими продуктами детонации, можно разделить на два этапа. На первом этапе усилие создается расширяющимися продуктами горения у закрытого конца детонационной трубки. До момента выхода детонационной волны из открытого конца в течение $10 \mathrm{~ms}$ датчик усилия регистрирует монотонное увеличение усилия до $5 \mathrm{~N}$. В момент выхода детонационной волны из открытого конца трубки происходит резкое повышение усилия до $11 \mathrm{~N}$. В течение второго этапа (10-50 ms) тяговое усилие создается в основном за счет истечения продуктов детонации из открытого конца трубки. Полный импульс $p=\int F d t$ рассчитывался до момента регистрации нулевого усилия $\sim 50 \mathrm{~ms}$. На диаграмме (рис. 3 ) представлены интегральные значения импульсов.

В отличие от гладкой трубки в спиралевидном канале тяговое усилие на закрытый конец снижается. В момент выхода детонационной волны из открытого конца трубки датчик усилия регистрирует повышение усилия с $5 \mathrm{~N}$ до $7-8 \mathrm{~N}$, что на 3-4N ниже, чем для гладкой трубки. На рис. 3 также представлены интегральные значения импульсов для трубки с расположенными внутри нее витыми лентами и плоской пластиной.

В отличие от преддетонационного расстояния использование витых лент практически не приводило к изменению импульса для смеси с $\mathrm{ER}=0.7$. Для всех типов лент и для гладкой трубки оно практически не изменялось и составляло $270 \pm 10 \cdot 10^{3} \mathrm{~N} \cdot \mathrm{s}$. Более того, сокращение длины шага витой ленты приводило к незначительному, на 8\%, повышению тягового усилия по сравнению с гладкой трубкой. Однако использование витых лент в смесях с ER $=1.0$ и $\mathrm{ER}=1.5$ приводило к снижению тягового усилия на 24-31\% по сравнению с гладкой трубкой. Данное снижение тяги обусловлено тем, что распространяющаяся детонационная волна и продукты детонации оказывают давление на витую ленту со стороны закрытого конца, создавая отрицательное усилие.

\section{Заключение}

На основе полученных данных можно сделать заключение о том, что использование витых лент для сокращения преддетонационного расстояния целесообразно для тех смесей, у которых ширина детонационной ячейки близка к значению внутреннего диаметра детонационной трубки. При этом повышение импульса регистрируется для водородно-воздушных смесей с избытком окислителя. Сокращение шага витой ленты приводит к снижению преддетонационного расстояния на $40-43 \%$ в случае, когда ширина детонационной ячейки больше поперечного размера витого канала. При этом ширина детонационной ячейки должна оставаться меньше диаметра детонационной трубки. Для таких смесей формирование детонации происходит на длине одного периода витой ленты, 100 или $200 \mathrm{~mm}$.

Работа проведена при поддержке Российского фонда фундаментальных исследований, № 15-38-70017, президиумом РАН, 31-2016 „Горение в взрыв“.

\section{Список литературы}

[1] Щелкин К.И. / Под ред. Н.Н. Семенова. М.: Военное изд-во MBC CCCP. 1949. 196 c.

[2] Porowski R., Teodorczyk A. // J. Loss Prevention in the Process Industries. 2013. Vol. 26. N 2. P. 374-379.

[3] Kuznetsov M., Ciccarelli G., Dorofeev S. et al. // Shock Waves. 2002. Vol. 12. N 3. P. 215-220.

[4] Thomas G.O., Williams R.Ll. // Shock Waves. 2002. Vol. 11. P. 481-492.

[5] Фролов С.М., Аксенов В.С., Авдеев К.А. и др. // Химическая физика. 2013. Т. 32. Вып. 12. С. 45-51.

[6] Фролов С.М., Шамшин И.О., Медведев С.Н., Дубровский А.В. // ДАН. 2011. Т. 438. Вып. 5. С. 640-643.

[7] Смирнов Н.Н., Бойченко А.П.// Физика горения и взрыва. 1986. Т. 22. Вып. 2. С. 65-67.

[8] Frolov S.M., Aksenov V.S., Shamshin I.O. // Proc. of the Combustion Institute. 2007. Vol. 31. N 2. P. 2421-2428.

[9] Otsuka S., Suzuki M., Yamamoto M. // J. Thermal Science. 2010. Vol. 19. N 6. P. 540-544. 